\title{
GROUND ROLL ATTENUATION USING ADAPTIVE SINGULAR VALUE DECOMPOSITION FILTERING IN THE f-k DOMAIN
}

\author{
Danilo S. Cruz ${ }^{1}$ and Milton J. Porsani²
}

\begin{abstract}
The land seismic data often have low signal-to-noise ratio due, among other factors, the presence of ground roll. It is a coherent noise present in seismograms that appears as linear events, with low frequencies and high amplitudes, low velocities and, in most cases, overlapping the reflections and harm both the processing and the interpretation of the data. In this work we present a filtering approach to attenuate the ground roll, which is based on the Singular Value Decomposition (SVD) method applied in the frequency (f-k) domain. Before filtering the data we applied the standard pre-processing procedure to the original seismograms: the static corrections, the spherical divergence and a gain to improving the quality of the seismic records. After application of the 2D Fourier transform, the SVD is applied to a small frequency range using a sliding window approach. The f-k filtered spectrum is obtained with the difference between the original spectrum and the predicted ones and the family of filtered traces is obtained by performing a 2D inverse Fourier transform. The method was applied on a land seismic line of Tacutu Basin located in northeastern part of Brazil. The results show that the method is effective for mitigating the ground roll and provides better results when compared to conventional filtering method f-k.
\end{abstract}

Keywords: ground roll attenuation, seismic processing, SVD filtering, f-k filtering.

RESUMO. Os dados sísmicos terrestres geralmente apresentam baixa razão sinal-ruído devido, entre outros fatores, à presença do ground rol/. Trata-se de um ruído dominado por altas amplitudes, baixas frequências, baixas velocidades e de caráter dispersivo, representado no domínio x-t como eventos lineares. Este ruído se sobrepõe às reflexões e prejudica tanto o processamento quanto a interpretação dos dados. Para atenuação do ground rol/, utilizamos uma técnica de filtragem adaptativa baseada no método Singular Value Decomposition (SVD) e aplicada no domínio f-k. Como parte do pré-processamento dos dados foram aplicadas a correção estática, a correção de divergência esférica além da aplicação de um ganho com intuito de melhorar a qualidade do registro sísmico. Em seguida, as famílias de ponto de tiro comum foram levadas para o domínio da frequência (f-k), através da transformada dupla de Fourier, e a filtragem SVD foi aplicada na forma de janelas deslizantes confinadas à faixa de frequências dominada pelo ground roll. 0 espectro f-k filtrado foi obtido tomando a diferença entre 0 espectro original e 0 espectro SVD predito com a primeira autoimagem. A família de traços filtrada no domínio x-té obtida através da transformada inversa dupla de Fourier. 0 método foi aplicado sobre uma linha sísmica terrestre da Bacia do Tacutu, localizada na parte norte do Brasil. Os resultados mostram que o método proposto é eficaz para atenuar o ground rol/ e fornece resultados melhores quando comparados ao método convencional de filtragem $\mathrm{f}-\mathrm{k}$.

Palavras-chave: atenuação do ground rol/, processamento sísmico, filtragem SVD, filtragem f-k.

\footnotetext{
1PETROBRAS / Universidade Federal da Bahia, Instituto de Geociências, Centro de Pesquisa em Geofísica e Geologia, Campus Universitário da Federação, 59070-900 Salvador, BA, Brazil - E-mail: danilofisico@hotmail.com

2Universidade Federal da Bahia, Instituto de Geociências, Centro de Pesquisa em Geofísica e Geologia, Campus Universitário da Federação, 59070-900 Salvador, BA, Brazil - E-mail: porsani@cpgg.ufba.br
} 


\section{INTRODUCTION}

In the oil industry the exploration risk associated with this activity depends strongly on the quality of the image used for interpretation. The seismic reflection method uses the propagation of seismic waves in the subsurface in order to delineate geological structures. This is the geophysical method most used in the petroleum industry, mainly due to its ability to record reflections associated with reflectors situated a few kilometers deep, so the geophysical method with better resolution and greater success for hydrocarbon prospecting. The superficial waves generated by seismic sources are usually regarded as noise. Their high amplitudes generally impair the visualization and processing of signals of interest, usually composed by compressional waves reflected from subsurface. Land seismic data usually show low signal-tonoise ratio due to the presence of ground roll, a term that refers to the Rayleigh surface waves. This type of wave appears in the form of coherent, linear seismograms derived events in the acquisition of two-dimensional and has as main characteristics the high amplitude, low frequency and temporal velocity and, in most cases, dispersion, that is the variation of velocity with frequency. The latter causes the ground roll present in long-term seismic traces, overlying the reflections. Many authors have shown that the ground roll can be attenuated and filtered by the design of the acquisition itself (Harlan et al., 1984; Anstey, 1986; Shieh \& Herrmann, 1990; Pritchett, 1991; Brown \& Baan, 2007). Each strategy may have logistical limitations or data already acquired not apply. One of the simplest approaches to filtering uses the problem of attenuation of the ground roll is filtering $f-k$ which is applied in the frequency domain and spatial wave number. The method f-k uses 2D Fourier transform (Embree et al., 1963; Wiggins, 1966) and the ground roll, represented by linear events with low speed, is mapped as lines in the $f-k$ domain and can therefore be filtered through a band-pass $2 \mathrm{D}$ filter. The disadvantage of this procedure comes from the fact that the filter also eliminates the references to reflection.

Singular value decomposition (SVD) is a technique based on coherence that provides both signal enhancement and noise suppression. This method has been implemented for various applications in seismic (Freire \& Ulrych, 1988; Kendall et al., 2005; Bekara \& Baan, 2007) proposed a SVD polarizing filter for attenuation of the ground roll multichannel data. Tyapkin et al. (2003) proposed the method given alignment (Liu, 1999) to the horizontal alignment of the coherent noise in one or more common shot section. At each time section, the noise is represented by the first self-image (with a given fraction of the total power). The remaining eigenimages represents the sign and this part transformed back to the original domain of time and space. Chiu \& Howell (2008) proposed a method for calculating SVD uses of eigenimages that represents the coherent noise in a window in space-time. Data located in the windows are transformed into analytical signal followed by an SVD to decompose the complex analytic signal in eigenimages that represents the coherent noise. Yarham et al. (2006) proposed a two-stage method for the identification and removal of ground roll using the curvelet transform. Melo et al. (2009) presented a method to filter the ground roll using a 2D filter time derivative. Bekara \& Baan (2007) proposed a local SVD approach to noise removal in which each data window, the signal is horizontally aligned in time, and after the SVD only the first self-image is maintained. Then the process is repeated the next window using a moving window with a fifty percent overlap.

The SVD filtering approach (Porsani et al., 2009) operates with the SVD decomposition of a subset of features extracted from a 2D seismic line or 3D seismic volume. Only a trace of the inside sliding window (2D or $3 \mathrm{D}$ ) associated with the first eigenimages, is chosen to represent the filtered trace. This procedure preserves the relative amplitude and enhances the continuity and coherence of reflection events and attenuates noise that is associated to other self-images that are discarded. The SVD filtering can be seen as a multichannel filtering method where each filtered trace guard degree of consistency with the immediately neighboring traces. This method preserves the relations of amplitude, phase and spatial correlation of seismic events, the time that eliminates the incoherent noise normally associated with recent eigenvalues. In this work, the methodology is similar however, the filtering is performed in the frequency domain, the sliding window is made of slices of frequency bands instead of traces.

\section{SVD FILTERING}

Consider the subset of $M$ selected seismic traces of the family of seismograms given by, $d\left(t, x_{n}\right), t=1, \ldots N_{t}$ and $n=1, \ldots, M$.

The data matrix

$$
\begin{aligned}
D= & {\left[\mathbf{d}_{1} \ldots \mathbf{d}_{M}\right] } \\
= & \left\{d\left(t, x_{1}\right), \ldots, d\left(t, x_{M}\right)\right\}, \\
& t=1, \ldots, N_{t}
\end{aligned}
$$

can be decomposed by using the SVD method (Golub \& Van Loan, 1996):

$$
\mathbf{D}=\mathbf{U} \boldsymbol{\Sigma} \mathbf{V}^{T}
$$

where $\mathbf{U}$ and $\mathbf{V}$ are unitary and orthogonal matrix such that $\mathbf{U}^{-1}=\mathbf{U}^{T}$ and $\mathbf{V}^{-1}=\mathbf{V}^{T}$; 
$\boldsymbol{\Sigma}=\operatorname{diag}\left\{\sigma_{1}, \cdots, \sigma_{M}\right\}$ is the matrix of eigenvalues $(M \times M)$, $\sigma_{1} \geq \sigma_{2} \geq \cdots \geq \sigma_{r} \geq 0$;

$\mathrm{U}=\left[\mathbf{u}_{1}, \cdots, \mathbf{u}_{M}\right]$ is the matrix of eigenvectors $\left(N_{t} \times M\right)$ associated with the time dimension;

$\mathrm{V}=\left[\mathbf{v}_{1}, \cdots, \mathbf{v}_{M}\right]$ is the matrix of eigenvectors $(M \times M)$ associated with the spatial dimension.

Making $\widehat{\mathbf{U}}=\mathbf{U} \boldsymbol{\Sigma}=\left[\sigma_{1} \mathbf{u}_{1}, \cdots, \sigma_{M} \mathbf{u}_{M}\right]$ we can rewrite the Eq. (2) as follows:

$$
\begin{aligned}
& {\left[\mathbf{d}_{1} \cdots \mathbf{d}_{j} \cdots \mathbf{d}_{M}\right]=\widehat{\mathrm{UV}^{T}} } \\
= & {\left[\sigma_{1} \mathrm{u}_{1} \cdots \sigma_{M} \mathrm{u}_{M}\right] \times\left[\begin{array}{c}
\mathrm{v}_{1}^{T} \\
\vdots \\
\mathrm{v}_{M}^{T}
\end{array}\right] } \\
= & {\left[\sigma_{1} \mathrm{u}_{1} \cdots \sigma_{M} \mathrm{u}_{M}\right] \times\left[\begin{array}{ccc}
v_{1,1} & \cdots & v_{1, M} \\
\vdots & \ddots & \vdots \\
v_{M, 1} & \cdots & v_{M, M}
\end{array}\right] }
\end{aligned}
$$

From where we have the equation for SVD decomposition of a single trace from the subset of $M$ traces of the original section

$$
\begin{aligned}
\mathbf{d}_{j} & =\left[\sigma_{1} \mathrm{u}_{1} \cdots \sigma_{M} \mathrm{u}_{M}\right]\left[\begin{array}{c}
v_{1, j} \\
\vdots \\
v_{M, j}
\end{array}\right] \\
& =\widehat{\mathbf{d}}_{1}^{j}+\cdots+\widehat{\mathbf{d}}_{k}^{j}+\cdots+\widehat{\mathbf{d}}_{M}^{j} \\
& =\sum_{k=1}^{M} \sigma_{k} \mathrm{u}_{k} v_{k, j}
\end{aligned}
$$

Note that the seismic trace $d\left(t, x_{j}\right)$, ( $j$ columns of the matrix D) can be obtained by linear combination of eigenvectors associated to the temporal dimension. The weights used in the linear combination coefficients are the eigenvectors of the spatial dimension scaled by the corresponding eigenvalues.

Another way of writing the Eq. (2) is as follows:

$$
\begin{aligned}
\mathrm{D} & =\left[\mathbf{u}_{1} \cdots \mathbf{u}_{M}\right]\left[\begin{array}{c}
\sigma_{1} \mathrm{v}_{1}^{T} \\
\vdots \\
\sigma_{M} \mathrm{v}_{M}^{T}
\end{array}\right] \\
& =\sigma_{1} \mathrm{u}_{1}^{T} \mathrm{v}_{1}^{T}+\cdots+\sigma_{M} \mathrm{u}_{M}^{T} \mathrm{v}_{M}^{T} \\
& =\widehat{\mathbf{D}}_{1}+\cdots+\widehat{\mathbf{D}}_{k}+\cdots+\widehat{\mathbf{D}}_{M} \\
& =\sum_{k=1}^{M} \widehat{\mathbf{D}}_{k}
\end{aligned}
$$

$\widehat{\mathbf{D}}_{k}=\sigma_{k} \mathbf{u}_{k} \mathbf{v}_{k}^{T}$ is the eigenimage $k$ of the data matrix D.

Equation (5) is the SVD representation of a single trace while the Eq. (6) is the SVD decomposition of all traces associated with the original data matrix. Limiting the summation in these equations we can obtain partial representations of each seismic trace or the seismic image. The first eigenvalues have greater amplitude causing the eigenimages associated preserve the features of higher spatial correlation (Freire, 1986). Thus the first eigenvectors are responsible for reconstitution of the predominantly horizontal or sub-horizontal events of greater magnitude.

$$
\widehat{d}_{k}^{j}=\sum_{k=1}^{K} \sigma_{k} u_{k}(t) v_{k}\left(x_{j}\right)
$$

Thus, the trace $\widehat{d}\left(t, x_{j}\right)$ obtained from the first $k$ eigenvectors represent the filtered trace. The small values of $K$ will be responsible for generating features, sections and volumes, that has higher spatial coherence. The SVD filtering can be seen as a multichannel method where each filtered trace guard certain degree of spatial coherence with the immediately neighboring traces.

The SVD filtering method proposed consists in the systematic application of Eq. (6) on all traces of a seismic line or a 3D volume, following the procedure:

- Selection of subset of M immediately neighboring traces each traces $d\left(t, x_{j}\right)$ the seismic section or volume.

- SVD decomposition

- Partial reconstruction of the traces $\widehat{d}\left(t, x_{j}\right)$ using only $k$ eigenvalues.

\section{SVD FILTERING IN f-k DOMAIN}

To apply SVD in the 2D frequency domain we move the data from $\mathrm{t}-\mathrm{x}$ to $\mathrm{f}-\mathrm{k}$ domain. The direct two-dimensional Fourier transform of a continuous function $f(x, t)$ is given by:

$$
F\left(k_{x}, \omega\right)=\int_{-\infty}^{+\infty} \int_{-\infty}^{+\infty} f(x, t) e^{i\left(k_{x}-\omega t\right)} d x d t
$$

Since the above transformation is reversible, we can obtain the function $f(x, t)$ through the inverse two-dimensional Fourier transform, e.g.:

$$
f(x, t)=\int_{-\infty}^{+\infty} \int_{-\infty}^{+\infty} F\left(k_{x}, \omega\right) e^{i\left(k_{x}-\omega t\right)} d k_{x} d \omega
$$

The seismic data is recorded as discrete signals, therefore we use the discrete Fourier transform. With the data in the $\mathrm{f}-\mathrm{k}$ domain, we choose the frequency band corresponding to the noise to be filtered. Figure 1 shows the $\mathrm{f}-\mathrm{k}$ spectrum of a shot-gather. We chose the range of $3 \mathrm{~Hz}$ to $15 \mathrm{~Hz}$ where the ground roll is dominant. A sliding window is used to perform the SVD filtering, as indicated in Figure 1. In the numerical results we have 


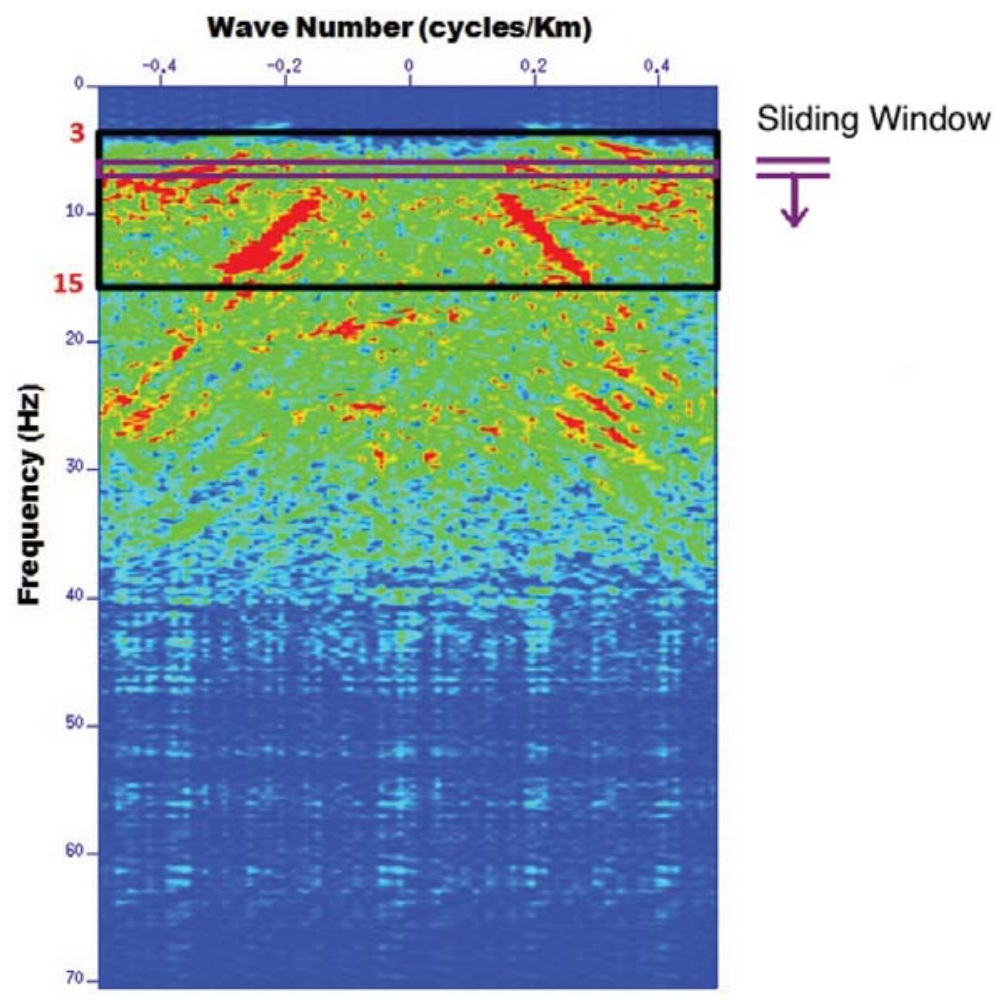

Figure 1 - Representation of f-k spectrum with selected frequency range (3-15) $\mathrm{Hz}$ and the sliding window used in the SVD filtering.

used a sliding window of 5 channels (columns). At each position of the window the matrix corresponding to the subset of data is decomposed using SVD and the central column of the first eigenimage is selected to be the predicted spectrum. The corresponding filtered spectrum is obtained taking the difference between the original spectrum and the predicted one. The SVD filtering is applied along the all range of frequency. We have iterate with this procedure before move back the data to the $t-x$ domain.

\section{RESULTS AND DISCUSSION}

Filtering was conducted in the $f-k$ domain, and the result was compared with the $\mathrm{f}-\mathrm{k}$ conventional by using the commercial sofware SEISSPACE (Landmark). These filters have been applied in a real seismic data, the line 050RL0090, located on the border between the Brazilian state of Roraima and Rupununi district in the Guiana. This seismic reflection line was obtained through continuous/sequential survey, using symmetric split-spread array 2500-150-0-150-2500, 96 channels were used, Have sampling rate of equal to $4 \mathrm{~ms}$, interval between shots equal to $200 \mathrm{~m}$ and geophone spacing equal to $50 \mathrm{~m}$. The sequence preceding the application of the methods of filtering process was as follows: (i) Geometry, (ii) static corrections of first breaks, and (iii) correction of spherical divergence.

The following figures illustrate the response to the application of this technique to ground roll attenuation. Figures $2 a, 2 b$ and $2 c$ show the input data, the data after 1 iteration of SVD filtering, and the difference between the input data (Fig. 2a) and filtered data (Fig. 2b). Figure 3 shows the amplitude spectrum of the previous figure. The analysis of the input data shows that the average amplitude spectra of the noise are well above those of the reflections, partially masked by the fact that application of AGC. In both figures it can be seen that the first iteration of the SVD filtering withdrew bit of ground roll, so the next step is to repeat the process.

Figures $4 b$ and $4 c$ show the result of SVD filtering after three iterations and the difference between the original input data (Fig. 2a) and the filtered (Fig. 4b). Figures $5 b$ and $5 c$ show the result of SVD filtering after five iterations and the difference between the original input data (Fig. 2a) and the filtered data (Fig. 5b). It may be noted that the extent to which the process is repeated, will be generated a given cleaner which allows better visualization of the reflections that were masked by ground roll. 


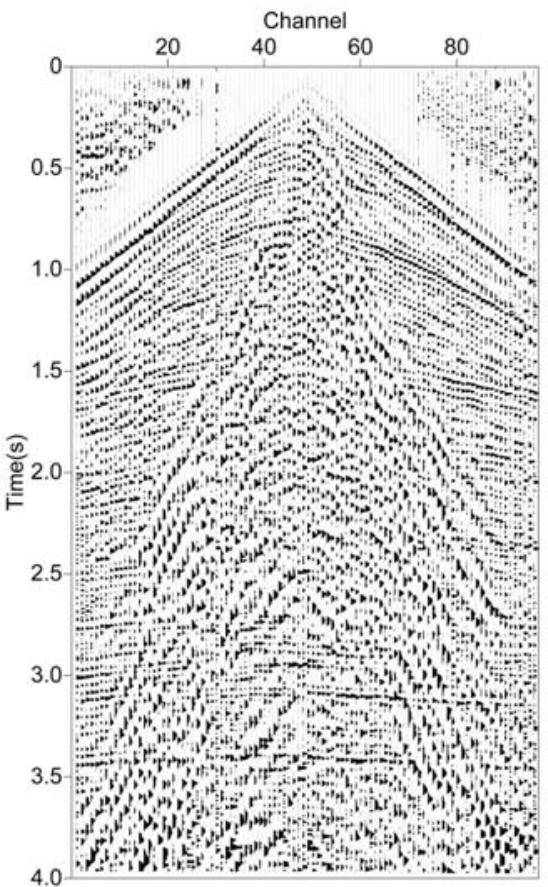

(a)

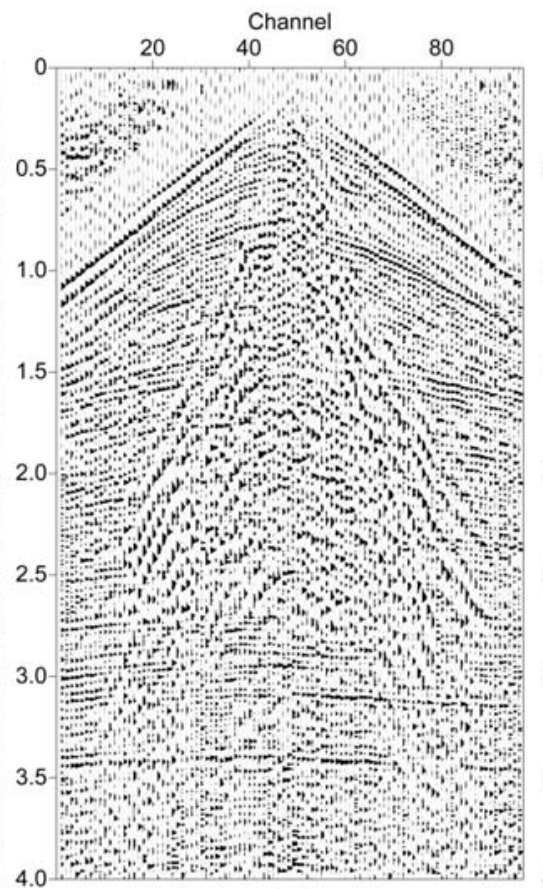

(b)

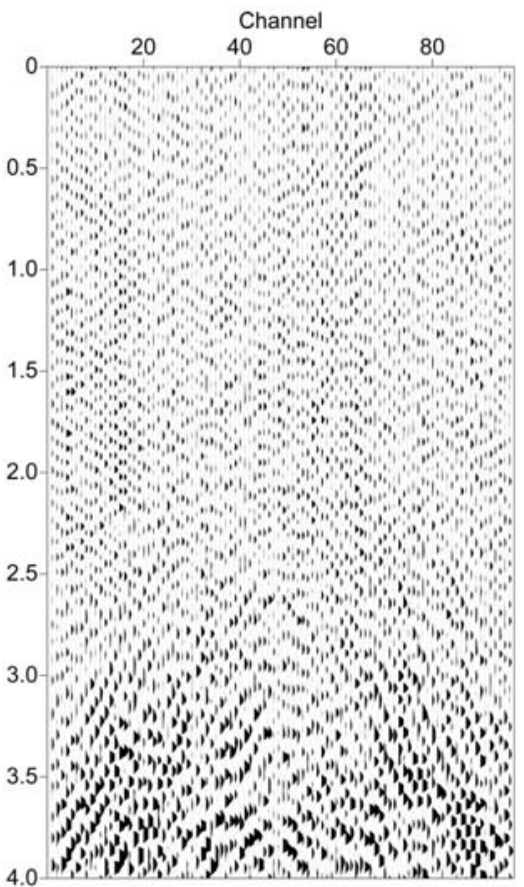

(c)

Figure 2 - Results of the adaptive SVD filtering in f-k domain of a shot-gather. Input data (a), filtered data after the first iteration (b) and removed noise (c).

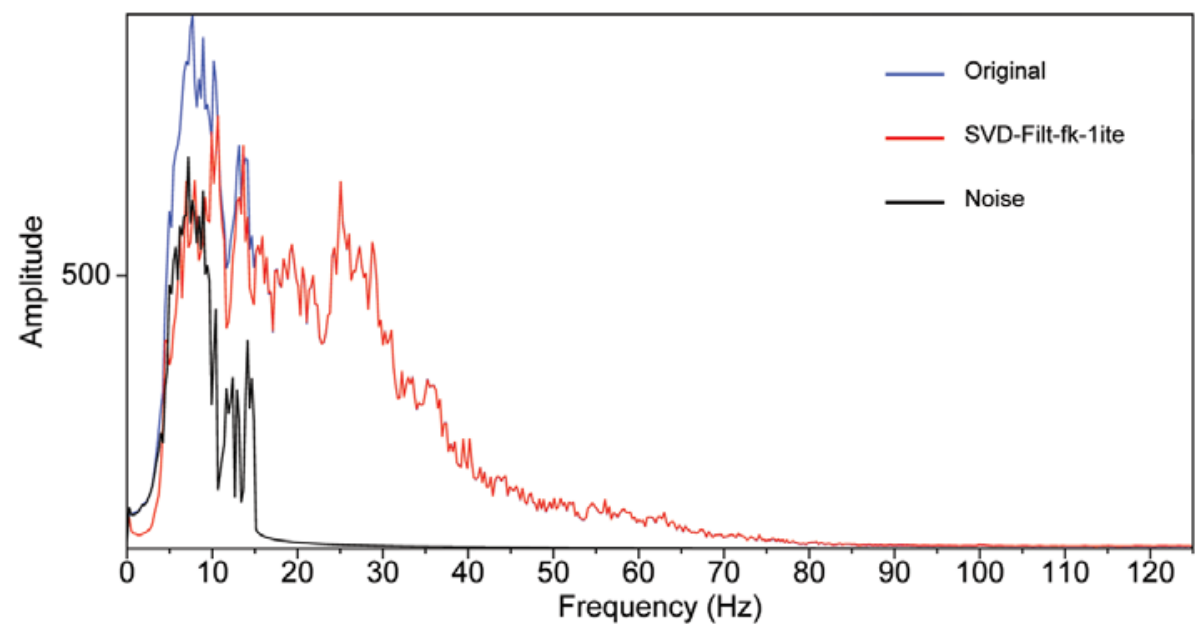

Figure 3 - Comparisons of the average amplitude spectra of data in Figure 2. Original (blue), after SVD filtering using one iteration (red), and the residue (black).

The analysis of the average amplitude spectra of the filtered data after three and five iterations are illustrated in Figures 6 and 7 show that the SVD filtering only acts on the (previously selected) frequency band and furthermore realizes that the frequencies are not zeroed but only attenuated which is an advantage compared to $f-k$ conventional.
Figures 8,9 and 10 show the stacked section obtained after applying the conventional and the SVD filtering approach both using data in the f-k domain. The analysis of the stacked sections allows comparing notice more clearly the effectiveness of the filtering process proposed in this work, and as promoted the improvement of spatial coherence and continuity of reflectors. 


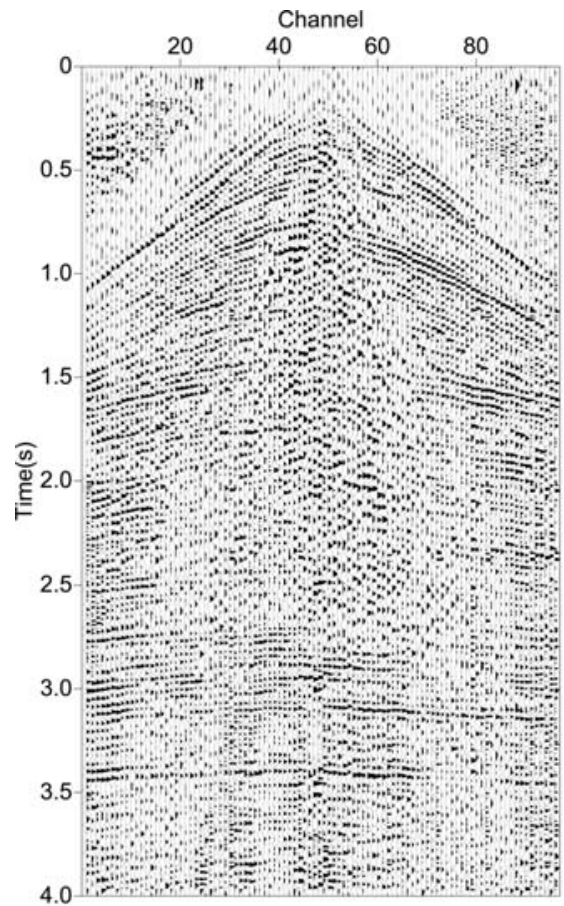

(a)

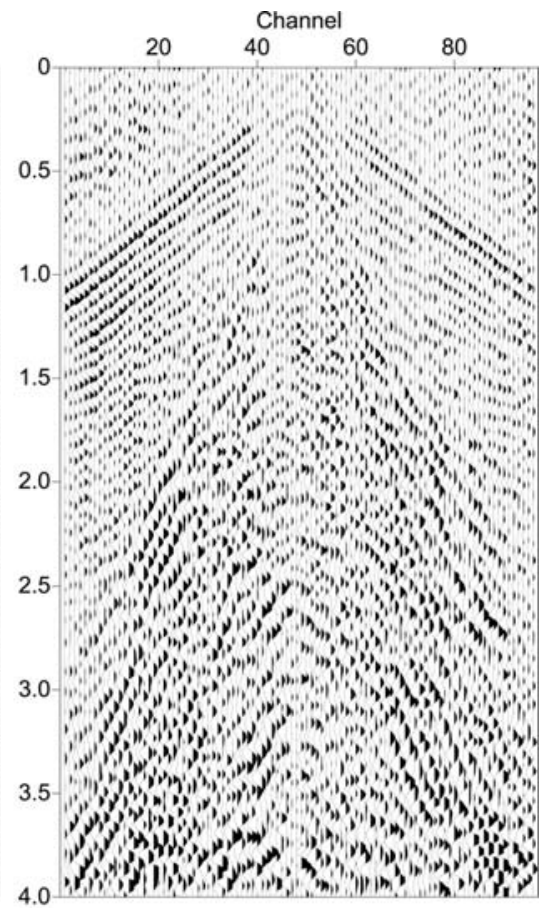

(b)

Figure 4 - Results of the adaptive SVD filtering in f-k domain of a shot-gather in Figure 2a. Filtered data after the three iterations (a) and removed noise (b).

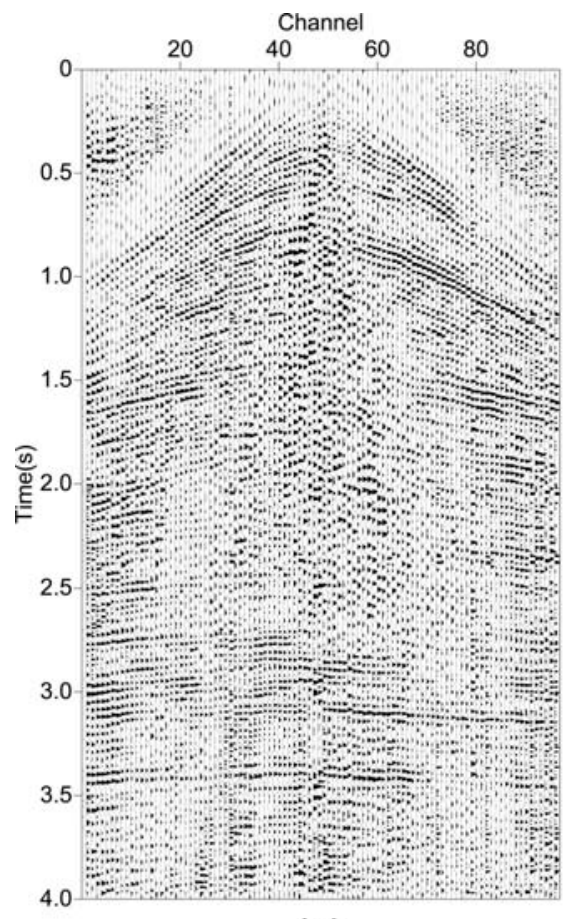

(a)

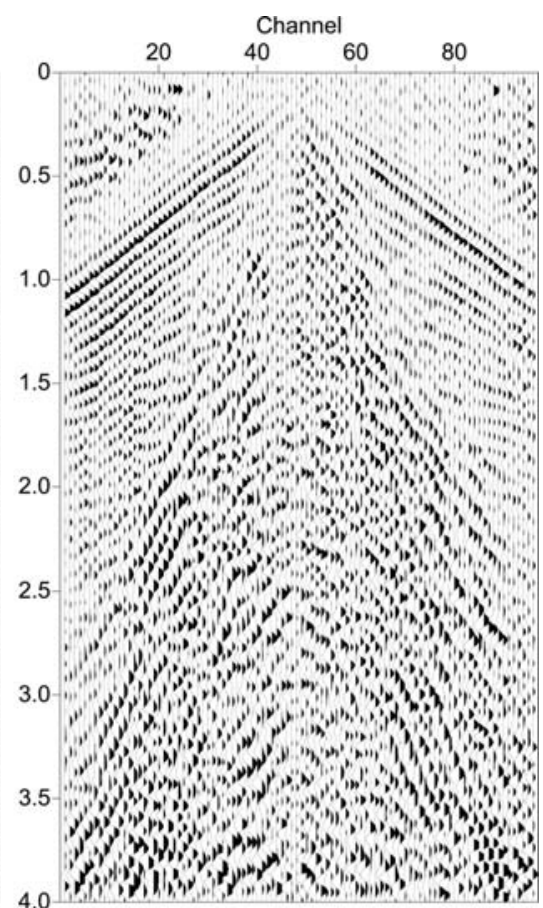

(b)

Figure $\mathbf{5}$ - Results of the adaptive SVD filtering in f-k domain of a shot-gather in Figure 2a. Filtered data after five iterations (a) and removed noise (b). 


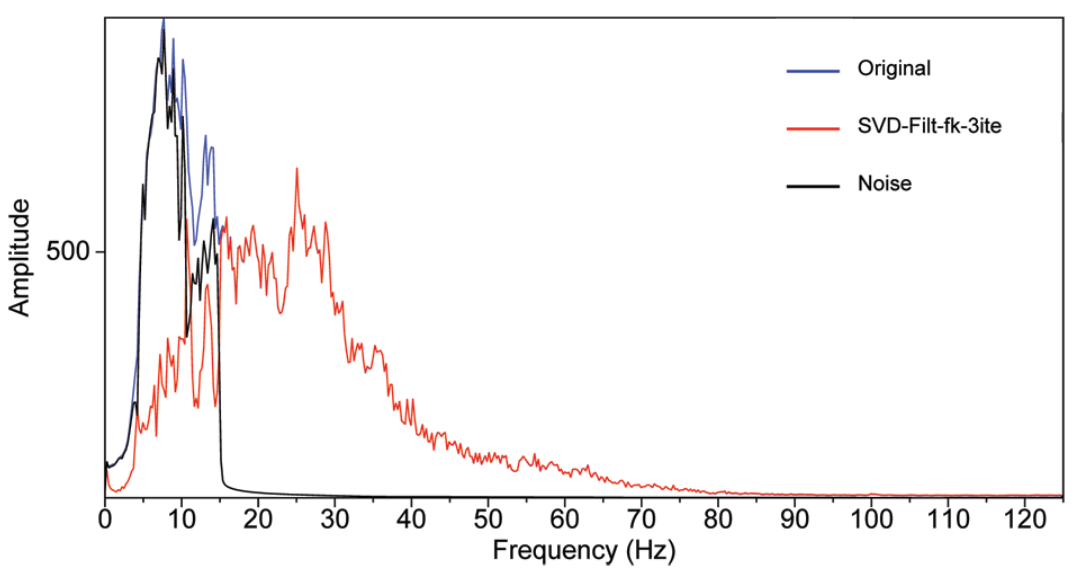

Figure 6 - Comparisons of the average amplitude spectra of data in Figure 4. Original (blue), after SVD filtering using three iterations (red), and the residue (black).

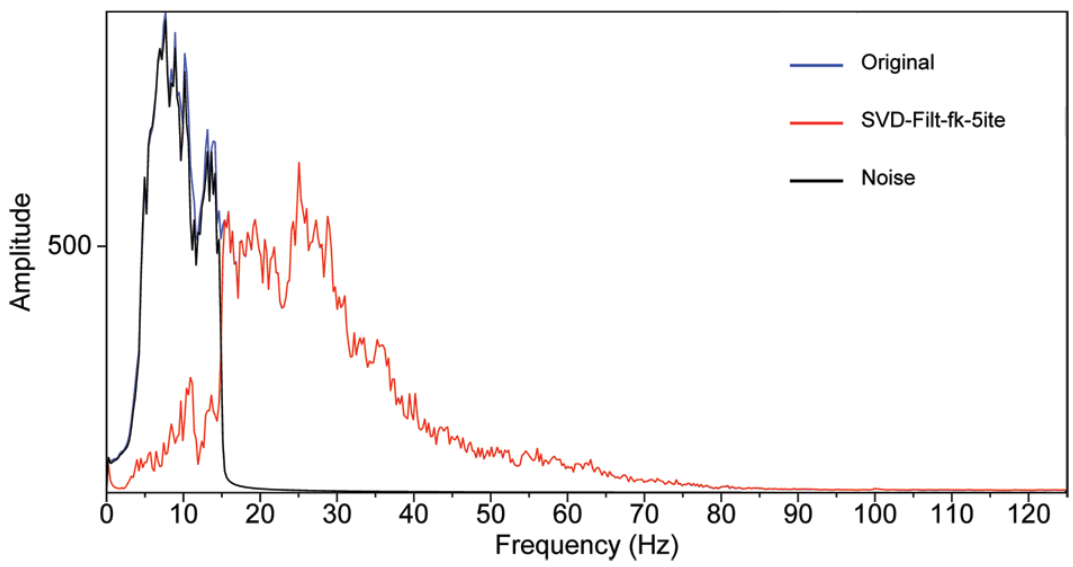

Figure 7 - Comparisons of the average amplitude spectra of data in Figure 5. Original (blue), after SVD filtering using five iterations (red), and the residue (black).

Despite the conventional $f-k$ method to promote some improvement in seismic data, this still falls short when compared to the SVD which presents a better seismic character.

Figure 11 shows a detail of the stacked sections. Again it is observed that the section with filtered SVD shows superior quality, with higher frequency resolution and better when compared with the other sections.

Finally it is worth mentioning that it is possible to perform this same filter in $\mathrm{f}-\mathrm{x}$ domain. You can also make the sliding window move in the direction of the wave number (or space if in the $\mathrm{f}-\mathrm{x}$ domain). Another option is to perform a $2 \mathrm{D}$ filtering. All these possibilities provide equivalent results, the quality of the result will depend on the chosen parameters.

\section{CONCLUSIONS}

The SVD filtering of pre-stacked seismic data in the frequency $(\mathrm{f}-\mathrm{k})$ domain, provided good results regarding the efficacy of the filtering to attenuate noise present in the data. This conclusion is clear from the analysis of seismic images in the numerical examples. This translates, in improving the continuity of reflectors (spatial coherence) and their better identification and tracking, valuing the stratigraphic sections and seismic line used in this work aspects. The results presented in this paper show that the method of adaptive SVD filtering of 2D seismic lines has improved the signal-to-noise ratio when it repeats the process. This improvement is the attenuation of ground roll without loss of information (reflection). For this it is necessary that the filter is properly parameterized, i.e the frequency band where the SVD filtering will act should be the band where noise is present. Also the number of iterations should be chosen wisely. This method was applied in the $f-k$ domain and present superior results when compared to the conventional $\mathrm{f}-\mathrm{k}$ method.

The results presented here show that the adaptive SVD filtering applied in the $\mathrm{f}-\mathrm{k}$ domain is efficient and can reveal features 


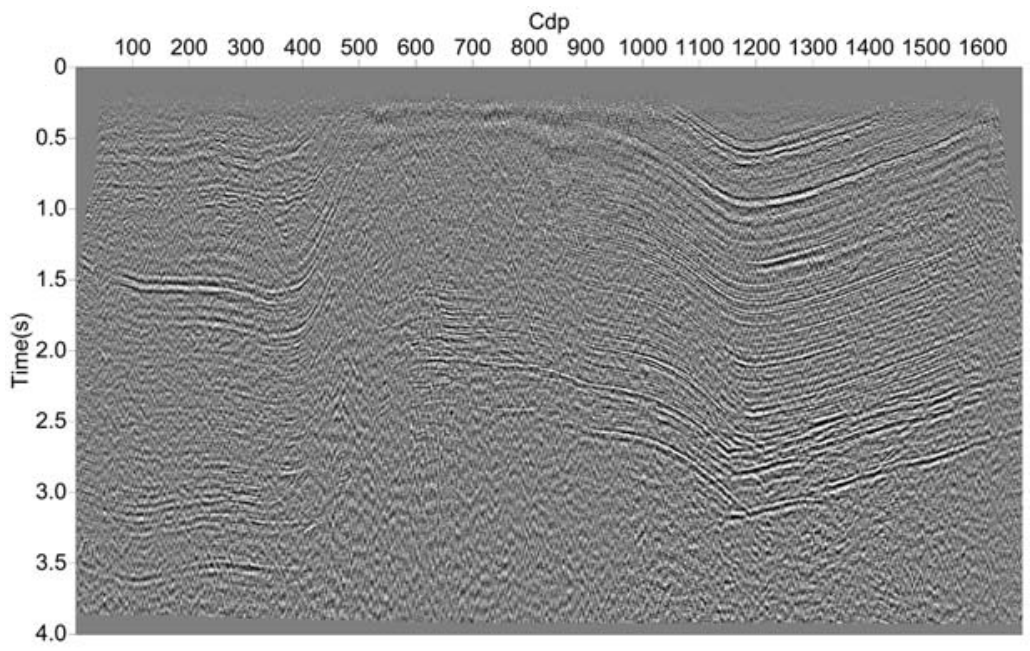

Figure 8 - Stacked section of the original data without filtering.

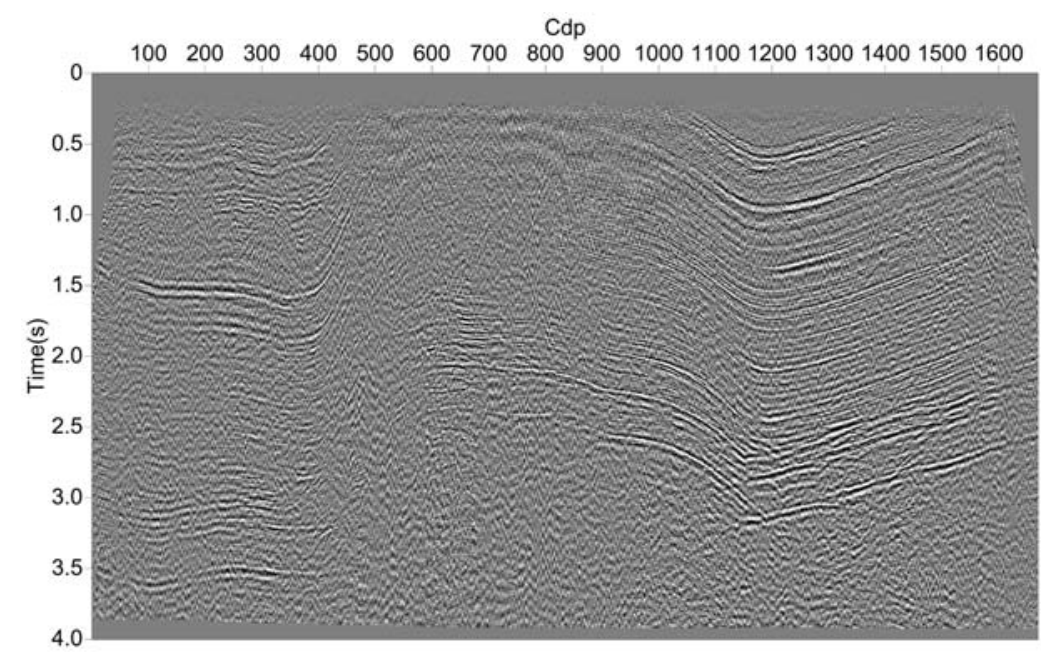

Figure $\mathbf{9}$ - Stacked section of the filtered data using the conventional f-k method.

Cdp

$100 \quad 200 \quad 300 \quad 400 \quad 500 \quad 600 \quad 700 \quad 8009001000110012001300140015001600$

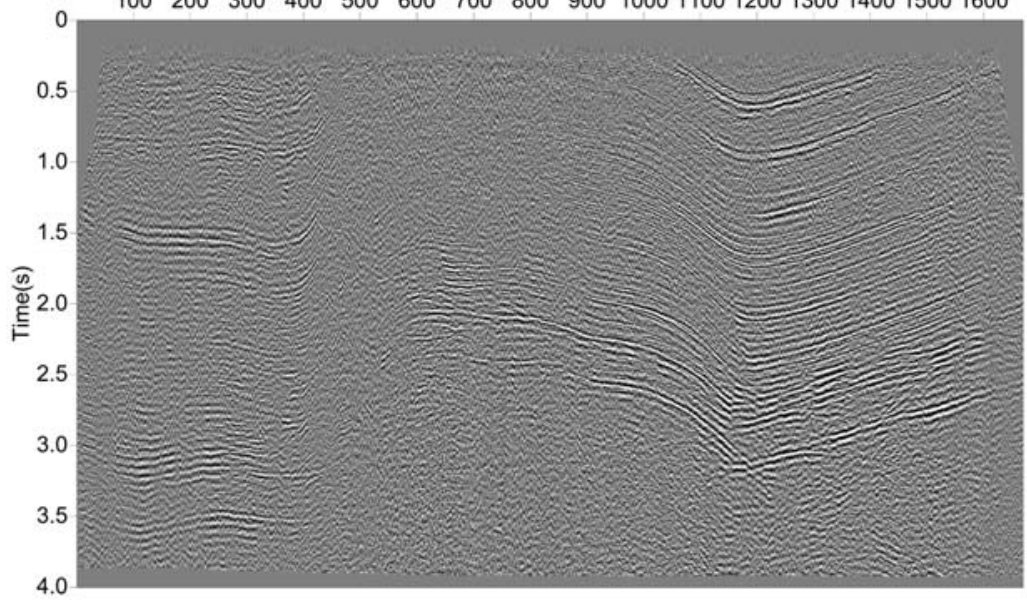

Figure 10 - Stacked section of the filtered data using the adaptive SVD filtering method using five iterations. 


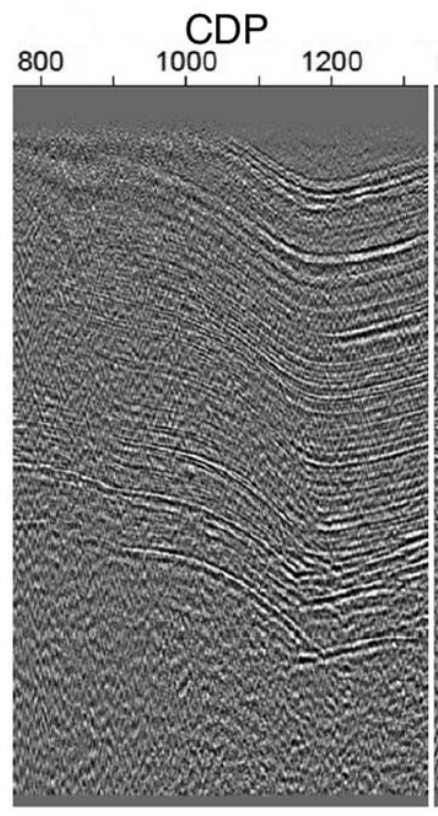

(a)

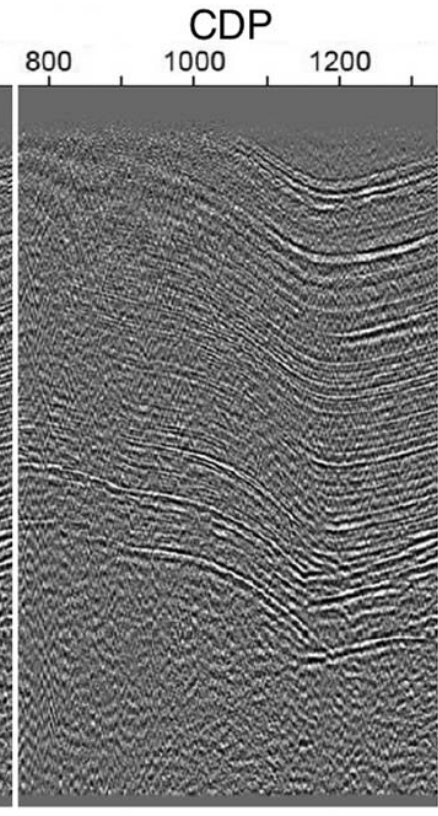

(b)

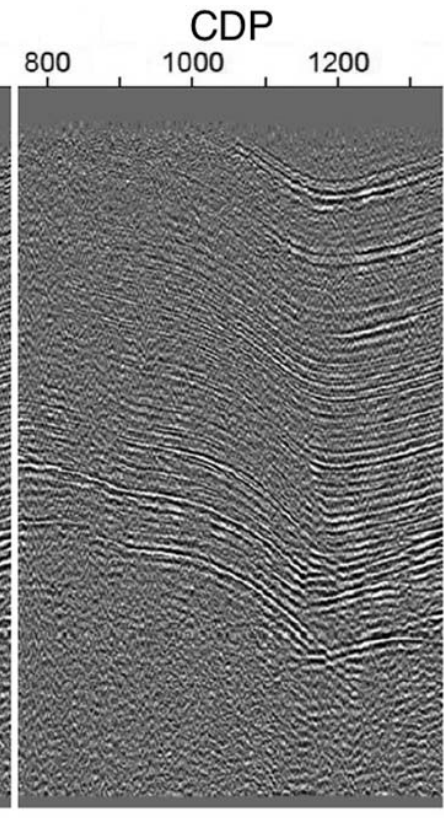

(c)

Figure 11 - Detail of stacked sections. (Fig. 10a) without filtering in (a), (Fig. 10b) conventional f-k in (b), and (Fig. 10c) adaptive SVD in f-k domain in (c).

and geological structures that were masked by noise present in the data. Because encourage improvements in the final image quality in seismic section, this filtering technique may help the interpreter in particular stratigraphic and structural analysis, during the work of interpretation of seismic sections in the search and identification of possible traps, making them potential targets promising the accumulation of hydrocarbons.

\section{ACKNOWLEDGEMENTS}

The authors thank INCT-GP/CNPq/MCT, PETROBRAS, ANP, FINEP, FAPESB Brazil for financial support and LANDMARK for the licenses granted to CPGG-UFBA.

\section{REFERENCES}

ANSTEY N. 1986. Whatever happened to ground roll? Leading Edge, 5: 40-45.

BEKARA M \& BAAN MV. 2007. Local singular value decomposition for signal enhancement of seismic data. Geophysics, 72: V59-V65.

BROWN M \& BAAN MV. 2007. Source-generated noise attenuation using the singular value decomposition. In: 70th Ann. Internat. Mtg., Soc. Expl. Geophys., Expanded Abstracts, 2103-2106.

CHIU SK \& HOWELL JE. 2008. Attenuation of coherent noise using localized-adaptive eigenimage filter. In: 78th Ann. Internat. Mtg., Soc.
Expl. Geophys., Expanded Abstracts, 2541-2545.

EMBREE P, BURG JP \& BACKUS M. 1963. Wide band velocity filtering the pie slice process. Geophysics, 28: 948-974.

FREIRE SLM. 1986. Aplicações do método de decomposição em valores singulares no processamento de dados sísmicos. Ph.D. Thesis. CPGG-UFBA. Available on: < http://www.pggeofisica.ufba.br/media/uploads/publicacoes/206.pdf> [PDF 14,41Mb]. Access on: February 02, 2015.

FREIRE SLM \& ULRYCH TJ. 1988. Application of singular value decomposition to vertical seismic profiling. Geophysics, 53: 778-785.

GOLUB GH \& VAN LOAN CF. 1996. Matrix Computations. 3rd ed. (Baltimore: Johns Hopkins University Press). Matrix Computations, Johns. $694 \mathrm{pp}$.

HARLAN WS, CLAERBOUT JF \& ROCCA F. 1984. Signal/noise separation and velocity estimation. Geophysics, 49: 1869-1880.

KENDAL R, JIN S \& RONEN S. 2005. An SVD-polarization filter for ground roll attenuation on multicomponent data. In: 77th Ann. Internat. Mtg., Soc. Expl. Geophys., Expanded Abstracts, 928-932.

LIU X. 1999. Ground roll suppression using the Karhunen-Loeve transform. Geophysics, 64: 564-566.

MELO PEM, PORSANI MJ \& SILVA MG. 2009. Ground-roll attenuation using a 2D time-derivative filter. Geophysical Prospecting, 57: 343-353. 
PORSANI MJ, SILVA MG, MELO PEM \& URSIN B. 2009. Ground-roll attenuation based on SVD filtering. In: 81th Ann. Internat. Mtg., Soc. Expl. Geophys., Expanded Abstracts, 3381-3385.

PRITCHETT W. 1991. System design for better seismic data. Leading Edge, 10: 30-35.

SHIEH C \& HERRMANN RB. 1990. Ground roll: rejection using polarization filters. Geophysics, 55: 1216-1222.

TYAPKIN YK, MARMALVEVSKYY NY \& GORNYAK ZV. 2003. Source- generated noise attenuation using the singular value decomposition. In: 75th Ann. Internat. Mtg., Soc. Expl. Geophys., Expanded Abstracts, 22, 2044

WIGGINS RA. 1966. $\omega$-k filter design. Geophysical Prospecting, 14: $427-440$

YARHAM C, BOENIGER U \& HERRMANN F. 2006. Curvelet-based ground roll removal. In: 76th Ann. Internat. Mtg., Soc. Expl. Geophys., Expanded Abstracts, 277-280.

Recebido em 20 janeiro, 2014 / Aceito em 14 outubro, 2015

Received on January 20, 2014 / Accepted on October 14, 2015

\section{NOTES ABOUT THE AUTHORS}

Danilo Santos Cruz. Received a B.Sc. in Physics (UFBA, 2004), M.Sc. in Physics (UFBA, 2007) and M.Sc. in Geophysics (UFBA, 2014). Has been working in Petrobras since 2006, on the Rio Grande do Norte-Ceará Operational Unit (UO-RNCE). Areas of interest include seismic modeling for aquisition, seismic data processing and seismic imaging.

Milton José Porsani. B.Sc. in Geology (USP, 1976). M.Sc. in Geophysics (UFPA, 1981). Ph.D. in Geophysics (UFBA, 1986). From 1986 to the present is the researcher CPGG-UFBA. Post doctorate in Geophysics at the Institute for Geophysics at the University of Texas, September/92 - October/93. Professor of Geology and Geophysics of IGEO-UFBA (1990). Professor in the field of oil exploration (2000). Researcher at CNPq. Coordinator of the oil exploration at CPGG-UFBA. Area of interest: Development of methods and algorithms for mono and multichannel filtering, seismic processing, inversion of geophysical data. 